\title{
PENERAPAN KNOWLEDGE MANAGEMENT SYSTEM PADA PERUSAHAAN OTOMOTIF : STUDI KASUS PT. ASTRIDO JAYA MOBILINDO
}

\author{
Rikaro Ramadi \\ Pasca Sarjana, Magister Ilmu Komputer \\ Universitas Budi Luhir \\ Email: rikaro.ramadi@gmail.com
}

\begin{abstract}
ABSTRAK
Perkembangan teknologi dan komunikasi yang semakin cepat menuntut manusia untuk bertindak semakin cepat dengan memperhatikan efisiensi dan efektifitas. PT. Astrido Jaya Mobilindo sebagai perusahaan yang bergerak di bidang otomotif kususnya penjualan dan sevices mobil. Tujuan yang diharapkan dari penelitian ini adalah membangun sistem informasi Knowledge Management System yang di gunakan untuk menyimpan dan memanfaatkan knowledge yang dimiliki karyawan sehingga mempermudah karyawan untuk menemukan solusi dari masalah yang di hadapi. Untuk metode pengumpulan data peneliti melakukan dengan cara observasi langsung, studi pustaka, dan wawancara. Knowledge management dilakukan dengan penciptaan pengetahuan, berbagi pengetahuan dan penerapan pengetahuan. Penciptaan pengetahuan dilakukan dengan model SECI (sosialization, externalization, combination dan internalization). Metode pengembangan system dengan Rapid Application Development (RAD) dan dimodelkan dengan menggunakan sistem analisis menggunakan Unified Modelling Language (UML). Pengujian validasi menggunakan Focus Group Discussion (FGD). Kualitas perangkat lunak yang dihasilkan di uji berdasarkan empat karakteristik kualitas perangkat lunak model ISO 9126, yaitu: functionality, reliability, usability, dan efficiency dengan menggunakan metode kuesioner. Teknik pengujian perangkat lunak dengan menggunakan software Acunetix dan Blackbox Testing. Hasil dari penilitian ini adalah menujukan bahwa penerapan knowledge management system adalah solusi dari permasalahan yang ada.
\end{abstract}

Kata kunci: knowledge management system, SECI, RAD, UML, FGD, ISO 9126.

\begin{abstract}
Technology development and communication faster demanding man to act the sooner by taking into account efficiency and the effectiveness of .PT Astrido jaya mobilindo as a company that working in the area of automotive kususnya sales and sevices car. A hoped-for goal from the study is to build information system knowledge management system which in use for storing and use knowledge owned employees so ease employees to find a solution of the problems. For data collection method researchers conducted by means of direct observation, the literature study, and an interview .Knowledge management conducted by the creation of knowledge, sharing knowledge and the application of knowledge.Knowledge creation done with model seci ( sosialization, externalization, combination and internalization ). metode development with rapid system application development $(R A D)$ and modeled by the use of systems analysis using the modelling language (UML).Validation of testing using focus group discussion (FGD). The quality of software that produced tested on four characteristic quality of software model iso 9126: functionality, reliability, usability, and efficiency by using the method the questionnaire Technique testing software as using software acunetix and blackbox testing. The result of research is showing that the implementation of knowledge management system are solutions of the existing problems.
\end{abstract}

Keywords: knowledge management system, SECI, RAD, UML, FGD, ISO 9126.

\section{PENDAHULUAN}

\subsection{Latar Belakang}

Perkembangan teknologi dan komunikasi yang semakin cepat menuntut manusia untuk bertindak semakin cepat dengan memperhatikan efisiensi dan efektifitas di segala bidang untuk menghadapi perkembangan tersebut tentu di perlukan fasilitas dan peralatan yang memadai. Sementara untuk mempercepat penemuan produk yang baru dan inovasi semakin tergantung pada penggunaan informasi 
dan teknologi pengetahuan yang canggih untuk membangun lingkungan yang mendukung proses inovasi yang sistematis dan efisien menurut Amidon (2002).

PT. Astrido Jaya Mobilindo sebagai perusahaan yang bergerak di bidang otomotif kususnya penjualan dan sevices mobil memiliki 15 cabang. Dengan banyaknya cabang tentu memiliki masalah yang berbeda-beda. Setiap hari kususnya divisi IT selalu menerima masalah dari cabang baik itu dari sisi software maupun hardware, setiap menangani masalah selalu membutuhkan waktu yang cukup lama dalam penanganan karena tidak adanya pendokumentasian atau aplikasi yang mampu menampung solusisolisi dari masalah yang ada. Setiap karyawan memiliki tugasnya masing-masing dimana pengetahuan karyawan yang satu belum tentu di miliki karyawan yang lainnya, ini mengakibatkan jika ada karyawan baru butuh waktu lama untuk beradaptasi dengan aplikasi yang ada, dan ketika karyawan lama keluar pengetahuan karyawan lama tidak dapat di kuasai sepenuhnya oleh karyawan lainnya atau hilang begitu saja.

\subsection{Masalah Penelitian}

\subsubsection{Identifikasi Masalah}

Permasalahan yang ada di PT. Astrido Jaya Mobilindo adalah tidak adanya pendokumentasian pengetahuan karyawan tentang masalah dan solusi yang ada sehingga masalah yang sama berulang kali harus melakukan pengecekan atau analisis yang cukup lama untuk mendapatkan solusi, maka untuk dapat mempercepat penanganan permasalahan tersebut dapat di selesaikan dengan Knowledge Management System.

\subsubsection{Batasan Masalah}

Mengingat luasnya bahasan tentang bisnis otomotif, maka dalam tesis ini hanya akan membahas Knowladge Management Sistem pada Divisi IT.

\subsubsection{Rumusan Masalah}

Bagaimana membangun sistem informasi knowledge management system pada PT. Astrido Jaya Mobilindo agar karyawan dapat menyimpan dan memanfaatkan knowledge yang ada.

\subsection{Tujuan dan Manfaat Penelitian}

\subsubsection{Tujuan Penelitian}

Tujuan yang diharapkan dari penelitian ini adalah membangun sistem informasi Knowledge Management System yang di gunakan untuk menyimpan dan memanfaatkan knowledge yang dimiliki karyawan sehingga mempermudah karyawan untuk menemukan solusi dari masalah yang di hadapi dimana masalah tersebut sudah pernah terjadi baik oleh karyawan itu sendiri maupun karyawan lainnya.

\subsubsection{Manfaat Penelitian}

Manfaat yang didapat dalam melakukan penelitian ini adalah sebagai berikut:

a) Manfaat Praktis

Hasil penelitian ini dapat memberikan pertukaran informasi pengetahuan kepada karyawan dalam hal menangani suatu masalah yang ada dan dengan cepat mendapatkan solusinya.

b) Manfaat Teoritis Penulisan tesis ini di harapkan dapat memberikan manfaat dan dapat dijadikan bahan referensi terkait dengan pokok pembahasan Knowlage Management System pada penelitian selanjutnya.

\section{LANDASAN PEMIKIRAN}

\subsection{Tinjauan Pustaka}

\subsubsection{Pengertian Knowledge}

Pengertian knowledge Menurut Davenport dan Laurence Prusak, knowledge adalah penggabungan antara pengalaman, nilai, informasi konstektual, pandangan dan instuisi para pakar yang membangun lingkungan dan kerangka evaliasi dan juga gabungan pengalaman dan informasi baru [6]. 


\subsubsection{Pengertian Knowledge Management}

Cut Zurnali mengemukakan bahwa untuk mendefinisikan knowledge benar-benar sulit sebagaimana menggabungkan banyak intangibles seperti pengalaman (experience), intuisi (intuition), pertimbangan (judgement), keahlian (skill), dan pelajaran yang dipelajari (lessons learned), yang secara potensial memperbaiki berbagai tindakan. Knowledge merupakan keadaan kognitif pikiran yang dicapai dengan menggabungkan pemahaman dan kognisi (understanding and cognition).

\subsubsection{Pengertian Knowledge Management System}

"Perusahaan yang sukses adalah yang konsisten menciptakan pengetahuan baru, membaginya keseluruh organisasi, dan semua orang tahu akan teknologi baru dan hasilnya" [7].

\subsubsection{Menumbuhkan Budaya Knowledge Sharing}

Knowledge management system merupakan strategi untuk meningkatkan efektifitas dan peluang/kesempatan pengembangan komptensi. Beberapa hal yang perlu dilakukan untuk menumbuhkan budaya berbagi pengetahuan diantaranya:

a) Menciptakan know-how dimana setiap pegawai berkesempatan dan bebas menentukan cara baru untuk menyelesaikan tugas dan berinovasi serta peluang untuk mensinergikan pengetahuan eksternal kedalam institusi.

b) Menangkap dan mengidentifikasi pengetahuan yang dianggap bernilai dan direpresentasikan dengan cara yang logis.

c) Penempatan pengetahuan yang baru dalam format yang mudah diakses oleh seluruh pegawai dan pejabat.

d) Pengelolaan pengetahuan untuk menjamin kekinian informasi agar dapat direview untuk relevansi dan akurasinya.

e) Format pengetahuan yang disediakan di portal adalah format yang user friendly agar semua pegawai dapat mengakses dan mengembangkan setiap saat.

\subsubsection{Konsep Dasar RAD}

RAD atau pengembangan aplikasi cepat adalah pendekatan berorientasi objek untuk pengembangan sistem yang meliputi metode pengembangan serta perangkat lunak [4]. Menurut Agustinus (2002), Rapid Application Development (RAD) adalah salah satu metode pengembangan suatu sistem informasi dengan waktu yang relatif singkat. Untuk pengembangan suatu sistem informasi yang normal membutuhkan waktu minimal 180 hari, akan tetapi dengan menggunakan metode RAD suatu sistem dapat diselesaikan hanya dalam waktu 30-90 hari.

a) RAD merupakan alat yang digunakan untuk menghasilkan layar dan menunjukkan aliran keseluruhan aplikasi.

b) Pengguna menyetujui rancangan dan menandatangani model visual.

c) Implementasi kurang karena pengguna membantu untuk merancang aspek bisnis dari sistem.

McLeod dan Schell [5] berpendapat bahwa $R A D$ merupakan metode yang memfokuskan pada kecepatan dalam pengembangan sistem untuk memenuhi kebutuhan pengguna atau pemilik sistem seperti prototyping namun mempunyai cakupan yang lebih luas.

Menurut Kendall dan Kendall [4] terdapat tiga fase dalam model pengembangan sistem RAD yang melibatkan pengguna dan analis dalam penilaian, perancangan, dan implementasi, yaitu:

1) Requirements Planning (Perencanaan Persyaratan)

2) Design Workshop

3) Implementation (Penerapan)

Dengan menggunakan RAD, terdapat beberapa tujuan berikut ini yang tidak akan dapat dicapai secara bersama-sama yaitu:

a) Kemungkinan terjadi kesalahan yang kecil, karena pihak pengembang tidak mempunyai hak untuk mengubah komponen-komponen yang digunakan dalam mengembangkan suatu sistem.

b) Tingkat kepuasan konsumen yang tertinggi, karena kebutuhan-kebutuhan sekunder dari konsumen harus dikorbankan supaya suatu sistem dapat diselesaikan sesuai jadwal. 
Biaya pengembangan yang termurah, karena dengan menggunakan komponen yang sudah ada dapat menyebabkan biaya yang lebih besar apabila dibandingkan dengan mengembangkan komponen sendiri.

\subsubsection{Analisis Dan Perancangan Berorientasi Obyek Dengan Unified Modeling Language}

Pada tahun 1994, Grady Booch dan James Rumbaugh sepakat bergabung untuk menggunakan metode pengembangan berorientasi objek dengan tujuan membuat proses standart tunggal untuk mengembangkan sistem berorientasi objek. Ivar Jacobson bergabung pada tahun 1995, dan mereka bertika focus membuat sebuah bahasa pemodelan objek standart sebagai ganti dari pendekatan atau metode berorientasi objek standar sebagai ganti dari pendekatan atau metode berorientasi objek standar. Berdasarkan kerja mereka dan hasil kerja lainya pada industry, Unified Modeling Langguange ( UML ) versi 1.0 dirilis pada tahun 1997. Unified Modeling Langguange ( UML) adalah satu kumpulan konvensi pemodelan yang digunakan untuk menentukan atau menggambarkan sebuah sistem software yang terkait dengan objek [5].

\subsubsection{Model Kualitas Perangkat Lunak Menurut ISO 9126}

Institute of Electrical and Electronic Engineers (IEEE) mendefinisikan kualitas perangkat lunak adalah tingkatan pada sistem, komponen, atau proses yang sesuai kebutuhan atau harapan dari pelanggan atau pengguna. Menurut definisi Steve McConnell's kualitas perangkat lunak dibagi dalam dua hal yaitu: kualitas internal dan kualitas eksternal. Karakteristik kualitas eksternal merupakan bagian-bagian dari suatu produk yang berhubungan dengan para pemakainya, sedangkan karakteristik kualitas internal tidak secara langsung berhubungan dengan pemakai.

Definisi kualitas menurut International Standards Organization (ISO) adalah totalitas fitur-fitur dan karakteristik-karakteristik dari produk atau layanan yang berpengaruh pada kemampuan untuk memenuhi kebutuhan tertentu. ISO menyoroti pada fitur-fitur dan karakteristik dari produk atau layanan dalam kemampuannya memenuhi kebutuhan yang ditentukan. menyediakan model yang berbasikan obyek dalam 3 konteks dasar yaitu: quality, requirements dan characteristics.

Kualitas perangkat lunak dapat dinilai melalui ukuran-ukuran dan metode-metode tertentu, serta melalui pengujian-pengujian software. Salah satu tolak ukur kualitas perangkat lunak adalah ISO 9126, yang dibuat oleh International Organization for Standardization (ISO) dan International Electrotechnical Commission (IEC). ISO 9126 mendefinisikan kualitas produk perangkat lunak, model, karakteristik mutu, dan metrik terkait yang digunakan untuk mengevaluasi dan menetapkan kualitas sebuah produk software, dapat diukur dengan menggunakan rumus sebagai berikut:

$$
\% \text { SkorAktual }=\frac{\text { SkorAktual }}{\text { SkorIdeal }} \times 100 \%
$$

Keterangan:

1) Skor aktual adalah jawaban seluruh responden atas kuesioner yang telahdiajukan.

2) Skor ideal adalah nilai tertinggi atau semua responden diasumsikan memilih jawaban dengan skor tertinggi.

Selanjutnya hasil tersebut diolah dan dihitung dengan kriteria yang telah ditetapkan dalam rancangan penelitian, yaitu:

Tabel 1. Kriteria persentase tanggapan responden terhadap skor ideal

\begin{tabular}{ll}
\hline \% Jumlah Skor & Kriteria \\
\hline $20,00 \%-36,00 \%$ & Tidak Baik \\
$36,01 \%-52,00 \%$ & Kurang Baik \\
$52,01 \%-68,00 \%$ & Cukup \\
$68,01 \%-84,00 \%$ & Baik \\
$84,01 \%-100 \%$ & Sangat Baik \\
\hline an: Batas bawah 20\% diperoleh dari 1/5 dari batas atas 100\%
\end{tabular}

\subsubsection{Definisi Forum Group Discussion}

Beberapa definisi tentang Focus Group Discussion, antara lain: 
1) Menurut Hoed (1995), Focus Group Discussion adalah metode penelitian yang bertujuan untuk mengetahui kecenderungan yang ada pada individu mengenai persepsi individu itu tentang suatu hal.

2) Menurut Litosseliti (2003), Focus Group Discussion adalah kelompok kecil yang terstruktur dengan partisipan yang telah dipilih dengan dipandu moderator. Focus Group Discussion ini disusun untuk tujuan menggali topik yang spesifik dan, pandangan dan pengalaman individu melalui interaksi kelompok.

\subsection{Tinjauan Studi}

Tabel 2. Tinjauan studi terdahulu yang relevan

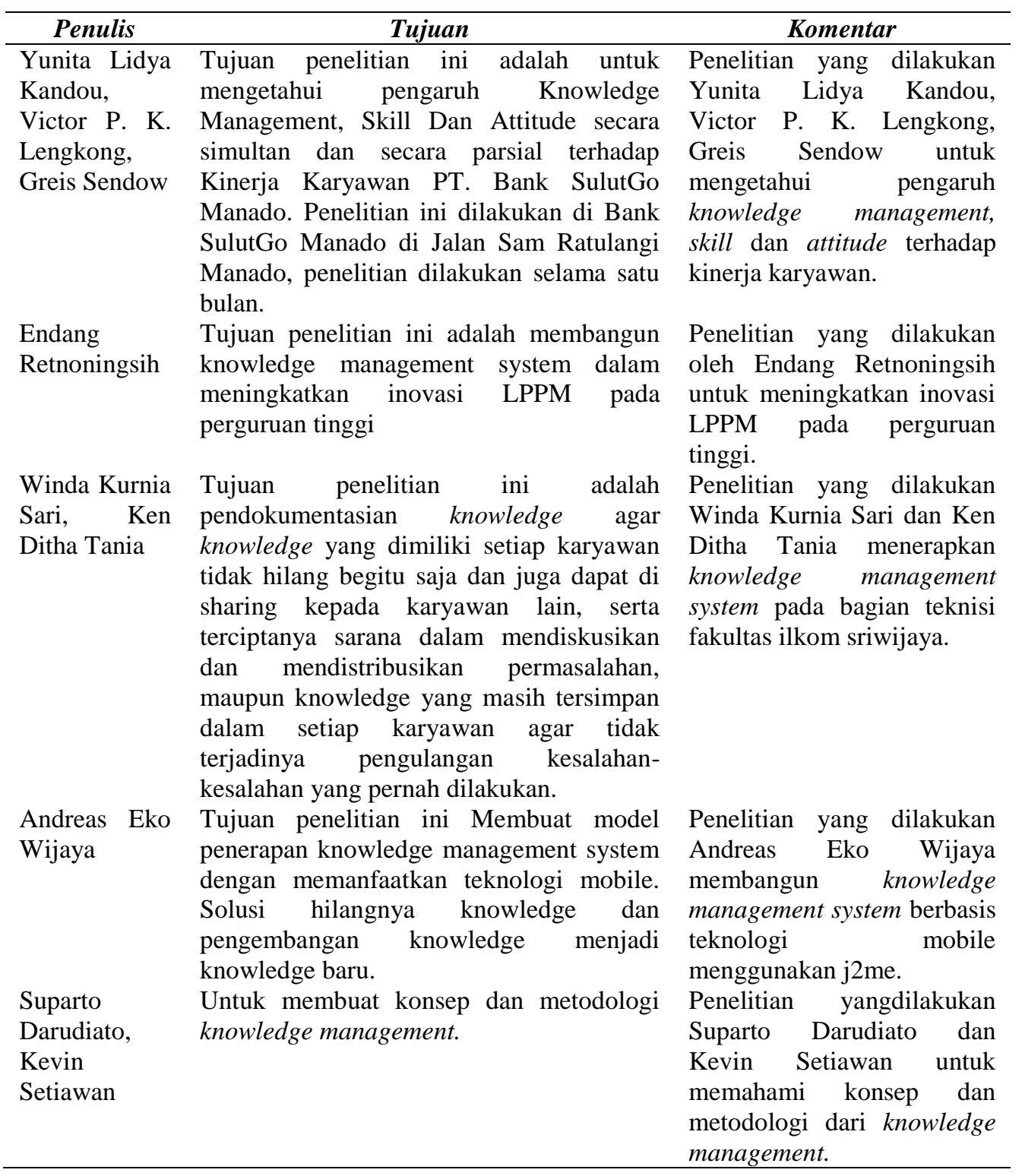

\subsection{Kerangka Konsep}

1) Latarbelakang, lamanya menemukan sulosi yang di hadapi oleh para karyawan PT. Astrido Jaya Mobilindo.

2) Identifikasi Masalah, waktu terbuand untuk menyelesaikan masalah yang sudah penah ada sebelumnya, sedangkan divisi it dituntut untuk memaksimalkan waktu untuk menangani suatu masalah.

3) Masalah, stadd IT membutuhkan cukup banyak waktu untuk mendapatkan solusi dari suatu masalah yang di hadapinya. 
4) Hipotesis, diduda system knowledge management system dapat menyelesaikan permalsahan yang dialami oleh para staff PT. Astrido Jaya Mobilindo

5) Teori, Mencari referenasi mengenai knowledge management system, dan perancangan system, serta referensi yang berkaitan dengan penelitian ini.

6) Tujuan, untuk menangi masalah dengan cepat dan tepat dengan membangun knowledge management system pada PT. Astrido Jaya Mobilindo.

7) Metodologi, melakukan pemecahan masalah dengan langkah-langkan untuk dirancang system informasi KMS.

8) Data dan Sumber Data, melakukan wawancara dan kuesioner pada divisi IT PT. Astrido Jaya Mobilindo.

9) Analisis, Pengolahan Skor data dan pengujian hipotesis.

10)Kesimpulan, Sistem Informasi KMS dapat didunakan untuk menangani permasalhan dengan cepet dan tepat.

Dari gambar diatas dapat dijelaskan bahwa permasalahan yang dihadapi yaitu, Banyaknya waktu yang terbuang untuk menyelesaikan suatu masalah yang di hadapi, dimana masalah tersebut sudah pernah terjadi sebelumnya.

\subsection{Hipotesis Penelitian}

Kondisi infrastruktur teknologi informasi yang ada pada PT. Astrido Jaya Mobilindo saat ini sudah sangat baik, maka diduga memungkinkan dilakukan Penerapan Knowledge management system yang akan dapat diimplementasikan dengan baik sehingga dapat menghasilkan peningkatan kinerja karyawan.

\section{DESAIN PENELITIAN}

\subsection{Metode Penelitian}

Menurut kamus besar bahasa Indonesia, penelitian adalah suatu kegiatan mengumpulkan, mengolahan, analisa dan penyajian data yang dilakukan dengan sistematis dan objektif untuk memecahkan suatu persoalan atau menguji suatu hipotesis untuk mengembangkan prinsip-prinsip umum. Adapun metode yang umum digunakan yaitu, tindakan penelitian, eksperimen, studi kasus dan survey.

Implementasi hasil analisis dan perancangan menggunakan pemrograman ASP.NET dan C\# dengan CMS DotNetNuke sebagai Corenya, sedangkan database menggunakan MS SQL Server 2008, untuk pengujian validasi menggunakan Focus Group Discussion, serta pengujian kualitas perangkat lunak yang dihasilkan mengadaptasi model ISO 9126 dan pengujian menggunakan software Acunetix serta blackbox testing.

Hasil penelitian berupa aplikasi Kenowledge Management System di PT. Astrido Jaya Mobilindo dapat langsung diterapkan sebagai solusi dari permasalahan yang dihadapi oleh perusahaan.

\subsection{Metode Pemilihan Sample}

Pada metode pengambilan sampel dalam penelitian ini, peneliti menggunakan metode purposive sampling. Pengambilan sampel dengan metode purposive sampling merupakan teknik pengambilan sampel dengan mengambil responden yang terpilih betul oleh peneliti menurut ciri-ciri spesifik yang dimiliki oleh sampel tersebut.

Responden dalam penelitian ini adalah Manger IT dan staff IT PT. Astrido Jaya Mobilindo. Pemilihan responden sampel ini dengan pertimbangan berdasarkan keterlibatan di dalam sistem sehingga pemilihan sample menjadi lebih tepat sasaran.

\subsection{Metode Pengumpulan Data}

Dalam penelitian ini untuk mendapatkan data yang diharapkan maka peneliti menggunakan beberapa metode pengumpulan data, yaitu :

1) Studi Pustaka

2) Tinjauan Lapangan 


\subsection{Teknik Analisa Data}

Setelah memilih metode penelitian, pemilihan sample penelitian, menentukan metode pengumpulan data langkah selanjutnya adalah menentukan teknik analisis data yang dilakukan dengan pendekatan deskriptif yaitu dengan menjabarkan fungsi KMS.

\subsection{Metode Pengembangan Sistem}

Metode pengembangan sistem yang akan ditulis dalam penelitian ini adalah metode Rapid Application Development (RAD). Tahapan-tahapan yang dilakukan dalam penelitian pengembangan aplikasi ini adalah:
1) Analisis
2) Perancangan
3) Pengembangan

\subsection{Langkah-Langkah Penelitian}

Untuk dapat melaksanakan penelitian maka dibutuhkan adanya kerangka kerja dalam melakukan langkah-langkah yang harus dilakukan sehingga pada akhirnya penelitian dapat diimplementasikan \& memberikan hasil laporan sesuai dengan simulasi yang dilaksanakan.Berikut ini merupakan langkahlangkah yang dilakukan peneliti di dalam penelitian ini:

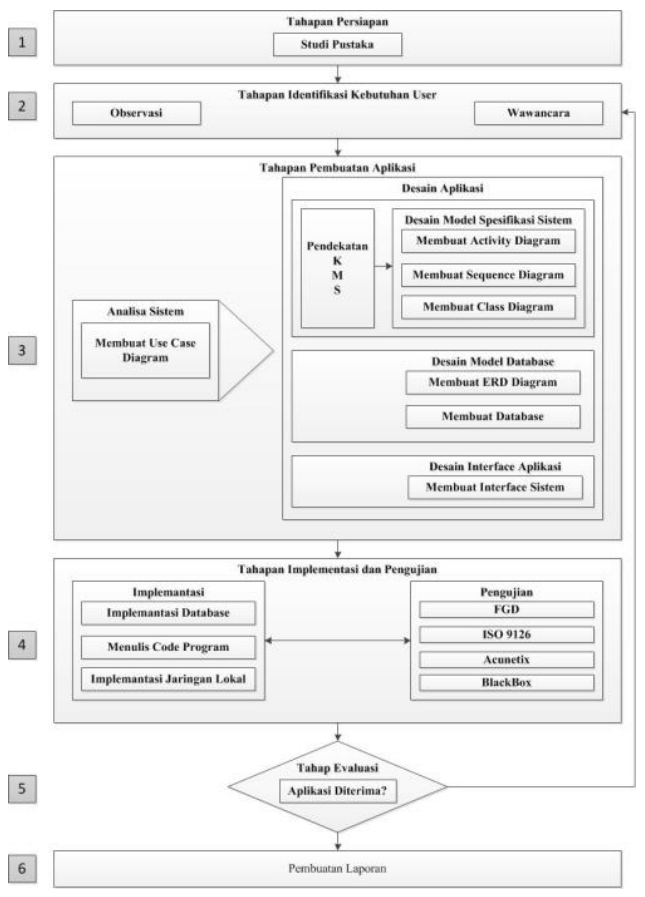

Gambar 1. Langkah-Langkah Penelitian

\subsection{Metode Pengujian}

\subsubsection{Pengujian dengan FGD (Focus Group Discussion)}

Pengujian sistem menggunakan metode FGD (Focus Group Discussion) ini di lakukan dengan cara melakukan test langsung terhadap sistem, yaitu di lakukan oleh pengguna KMS dengan melakukan login dan melakukan testing terhadap modul-modul yang ada sehingga dapat di ketahui apakah sistem memenuhi kebutuhan pada PT. Astrido Jaya Mobilindo.

\subsubsection{Pengujian Kualitas Dengan Mengadaptasi ISO 9126}

Pengujian sistem mengadaptasi standar kualitas perangkat lunak menurut ISO 9126 untuk menguji kualitas penerapan kenolage management system pada PT. Astrido Jaya Mobilindo. Penelitian ini hanya meneliti empat karakteristik yang terdapat pada ISO 9126, yaitu fungsionalitas, kebergunaan, efisiensi, 
dan portabilitas. Teknik pengujian (testing) dan evaluasi yang dilakukan dalam penelitian ini dengan cara sebagai berikut:

1) Pengujian Sistem. Berdasarkan empat karakteristik yang terdapat pada ISO 9126, yaitu fungsionalitas, kebergunaan, efisiensi, dan portabilitas. Dilakukan dengan menggunakan kasus uji yang dijalankan pada sistem.

2) Pengujian Penerimaan Pengguna. Dilakukan menggunakan Kuesioner yang dibagikan kepada pengguna sistem yaitu manager IT dan staf IT yang terlibat dalam penggunaan sistem KMS di PT. Astrido Jaya Mobilindo terdiri dari pertanyaan pertanyaan yaitu:

a. Pertanyaan-pertanyaan yang berkatian berguna untuk menguji fungsionalitas sistem.

b. Pertanyaan-pertanyaan yang berkaitan dalam menguji kecepatan layanan informasi.

\subsubsection{Pengujian Dengan Software Acunetix}

Software Acunetix merupakan salah satu tools yang direkomendasikan dan banyak di pakai oleh pakar security dan developer web untuk memeriksa keamanan dari website yang mereka bangun. Dalam penggunaannya software Acunetix sangatlah user friendly sehingga mudah digunakan, langkah awalnya kita hanya memasukkan alamat website yang akan di scan kemudian Acunetix akan melakukan tugasnya dengan sendirinya. Lamanya proses scanning tergantung dari besarnya webiste. untuk aplikasi web sederhana dan standar rata-rata acunetix membutuhkan waktu 15-30 menit untuk memeriksa setiap celah keamanan.

Tidak hanya sebatas memeriksa Acunetix juga akan memberikan rekomendasi untuk perbaikan dari setiap celah yang ditemukan. Aplikasi ini juga akan memeriksa setiap Folder yang ada dalam website, sangat baik jika dilakukan dalam jaringan lokal / localhost sebelum melakukan hosting.

\subsubsection{Pengujian Kualitas dengan BlackBox}

Pengujian penerapan knowlage managemen system pada PT. Astrido Jaya Mobilindo juga di lakukan dengan cara pengujian dengan teknik Blackbox, Pengujian black box adalah pengujian aspek fundamental sistem tanpa memperhatikan struktur logika internal perangkat lunak. Metode ini digunakan untuk mengetahui apakah sistem berfungsi dengan baik atau tidak. Pengujian black box merupakan metode perancangan data uji yang didasarkan pada sepesifikasi sistem yang diteliti atau dibuat.

\section{PEMBAHASAN HASIL PENELITIAN}

\subsection{Analisis Sistem}

Proses analisis sistem mendeskripsikan apa yang harus dilakukan oleh sistem untuk memenuhi kebutuhan informasi pengguna. Analisis sistem akan menjawab pertanyaan apa yang akan dikerjakan oleh sistem, siapa yang akan menggunakan sistem, dan dimana serta kapan sistem tersebut akan digunakan. Kegiatan analisis sistem yang berjalan dilakukan dengan pendekatan analisis berorientasi objek untuk sistem yang dirancang, dimaksudkan untuk menitik beratkan kepada fungsionalitas sistem yang berjalan. Peneliti dalam hal ini juga menggunakan pendekatan metode Top-Down dalam menganalisa kebutuhan pengguna dalam pemebuatan system ini. Selanjutnya dari hasil analisis akan divisualisasi dan didokumentasikan dengan Unified Modeling Language (UML) melalui Use Case Diagram, Activity Diagram, dan Sequence Diagram dengan pertimbangan diagram tersebut dianggap mewakili secara keseluruhan sistem yang berjalan yang dapat dimengerti oleh pengguna.

\subsubsection{Analisis Kebutuhan Fungsional Dan Non Fungsional}

1) Kebutuhan Fugsional dan Non Fungsional Pengguna

Setelah melakukan observasi dan wawancara terhadap staff dan eksekutif, peneliti mengalami kendala karena banyaknya permintaan fitur yang di minta oleh staff dan eksekutif dalam pembuatan sistem ini. Namun peneliti melakukan proses elisitasi terhadap kebutuhan fungsional dan non fungsional agar di dapatkan beberapa kebutuhan yang sebenarnya dibutuhkan oleh pengguna. Kebutuhan-kebutuhan tersebut adalah sebagai berikut: 
Tabel 3. Elisitasi fuctional \& nonfunctional draft

\begin{tabular}{|c|c|c|}
\hline \multicolumn{2}{|c|}{ Functional (User ingin sistem dapat:) } & NonFunctional (Saya ingin sistem dapat:) \\
\hline 1 & $\begin{array}{l}\text { Dapat di akses oleh eksekutif dan } \\
\text { staff. }\end{array}$ & 1 Menampilkan halaman login \\
\hline 2 & $\begin{array}{l}\text { Dapat memasukan knowledge } \\
\text { kedalam system }\end{array}$ & $\begin{array}{l}\text { Menampilkan guide cara pemakaian } \\
\text { aplikasi }\end{array}$ \\
\hline 3 & $\begin{array}{l}\text { Dapat menampilkan knowledge } \\
\text { yang ada }\end{array}$ & Mudah dalam Pengoperasiannya \\
\hline 4 & $\begin{array}{l}\text { Dapat memberikan komentar pada } \\
\text { knowledge yang dilihat }\end{array}$ & $\begin{array}{l}\text { Menampilkan pesan jika } \\
\text { penginputan }\end{array}$ \\
\hline 5 & $\begin{array}{l}\text { Dapat melakukan chatting dalam } \\
\text { suatu group discution }\end{array}$ & $\begin{array}{l}\text { Menggunakan ASP.NET } \\
\text { perancangan aplikasi }\end{array}$ \\
\hline 6 & $\begin{array}{l}\text { Dapat melakukan private chat } \\
\text { antar user }\end{array}$ & bahasa pem \\
\hline 7 & $\begin{array}{l}\text { Dapat mengirimkan email antar } \\
\text { user }\end{array}$ & $\begin{array}{l}\text { manan yang cukup untuk } \\
\text { dibuat }\end{array}$ \\
\hline 8 & Adanya menu setting user & $\begin{array}{l}\text { Menggunakan MS SQL Server untuk } \\
\text { databasenya }\end{array}$ \\
\hline 9 & Adanya menu & $\begin{array}{l}\text { ilkan tampilan yang sederhana } \\
\text { friendly }\end{array}$ \\
\hline & Adanya menu profile & Menggunakan Webserver IIS \\
\hline
\end{tabular}

2) Use Case Diagram

Berdasarkan spesifikasi kebutuhan fungsional dan actor yang terlibat dalam sistem, maka dapat dimodelkan dengan use case diagram. Use case diagram menggambarkan fungsionalitas yang diharapkan dari sebuah sistem. Use case juga menggambarkan interaksi yang terjadi dalam sistem, yang memberi gambaran user atau actor yang berhubungan dengan sistem dan hal-hal yang berhubungan dengan user di dalam sistem.

a) Actor

Actor adalah segala sesuatu yang berinteraksi langsung dengan sistem aplikasi komputer, seperti orang, benda atau lainnya. Tugas actor adalah memberikan informasi kepada sistem dan dapat memerintahkan sistem agar melakukan suatu tugas. Berdasarkan identifikasi kebutuhan pengguna.

b) Use Case

Use case adalah deskripsi fungsi dari sebuah system dari perspektif pengguna. Use case bekerja dengan cara mendeskripsikan tipikal interaksi antara pengguna sebuah system dengan sistemnya sendiri melalui sebuah cerita bagaimana sebuah sistem dipakai. Pada analisis dan pemodelan kebutuhan fungsional membutuhkan pemecahan menjadi beberapa Menu untuk memudahkan dalam mendeskripsikan pemahaman setiap proses dalam sistem. Terdapat 9 Menu atau modul untuk pemodelan dengan use case diagram, yaitu: Login, Home, Chat, My Profile, Messege, My Knowledge, Setting, User, Roles.

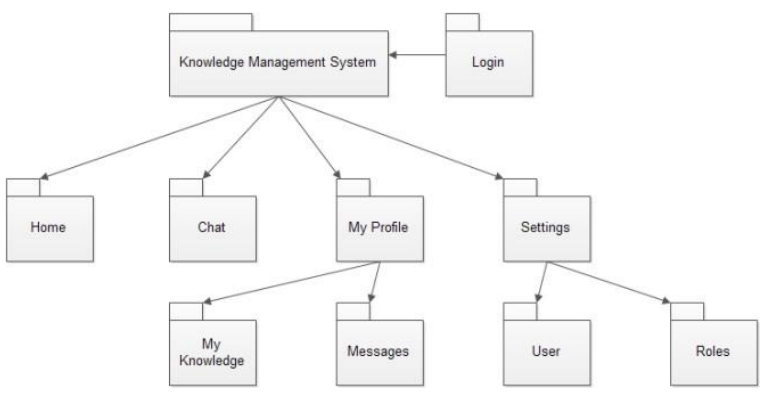

Gambar 1. Menu Untuk Use Case Diagram 


\subsubsection{Analisa Perilaku Sistem}

1) Activity Diagram

Activity Diagram merupakan model analisis yang digunakan atau menggambarkan sebuah proses aktivitas. Dalam penelitian ini, activity diagram digunakan untuk memodelkan suatu proses atau operasi, diagram ini dipakai untuk menggambarkan logika dari sebuah proses atau operasi. Activity Diagram menjelaskan tentang alur aktifitas didalam sistem yang sedang dirancang, bagaimana alur berawal, bagaimana keputusan-keputusan dapat terjadi dan terakhir bagaimana sistem berakhir. Dalam penelitian ini peneliti menggambarkan activity diagram tersebut melalui interaksi antara actor dengan sistem yang akan dibangun. Dengan demikian, activity diagram diturunkan dari setiap use case yang sudah dibuat sebelumnya, untuk menggambarkan masingmasing prosedur dalam Penerapan knowledge management system pada PT. Astrido Jaya Mobilindo.

2) Sequence Diagram

Pada Sequence Diagram menjelaskan aliran fungsionalitas dalam use case. Sebuah sequence diagram menunjukkan urutan interaksi object yang disusun dalam urutan waktu. Ini menggambarkan object dan class-class yang terlibat dalam skenario dan urutan pesan yang dipertukarkan antara object yang dibutuhkan untuk melaksanakan fungsi skenario. Kegunaannya untuk menunjukkan rangkaian pesan yang dikirim antara object juga interaksi antara object, sesuatu yang terjadi pada titik tertentu dalam eksekusi sistem.

\subsection{Perancangan Sistem}

Perancangan sistem menentukan bagaimana sistem akan memenuhi tujuan tersebut, dalam hal ini: perangkat keras, perangkat lunak, infrastruktur jaringan; antarmuka pengguna serta program-program khusus, database, dan file yang akan dibutuhkan. Perancangan sistem merupakan tahap lanjutan dari analisis sistem dimana pada perancangan sistem digambarkan sistem yang akan dibangun sebelum dilakukan pengkodean dalam suatu bahasa pemrograman. Dalam perancangan suatu sistem tidak lepas dari hasil analisa, karena dari hasil analisa sistem baru dapat dibuat suatu rancangan sistem.

\subsubsection{Perancangan Spesifikasi Program Dengan Class Diagram}

Class Diagram menampilkan beberapa class pada sistem ini dan memberikan gambaran tentang sistem dan relasi-relasi didalamnya. Disini juga dimasukkan himpunan bagian (subset) dari class-class, yaitu atribut-atribut dan operasi-operasi dalam suatu class. Berikut ini class diagram untuk Penerapan Knowledge Management System yang dirancang:

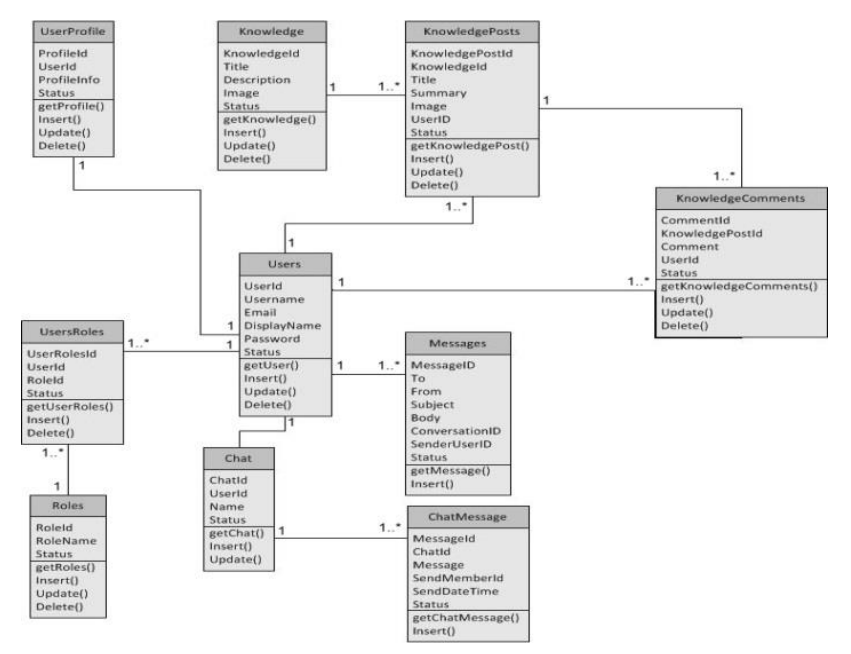

Gambar 3. Class Diagram

\subsubsection{Perancangan Database}

Perancangan database yaitu merancang data yang terhubung dan disimpan secara bersama-sama. Untuk menggambarkannya digunakan diagram relasi. berikut adalah gambar diagram relasi pada Kwonledge management system pada Pt. Astrido Jaya Mobilindo. 


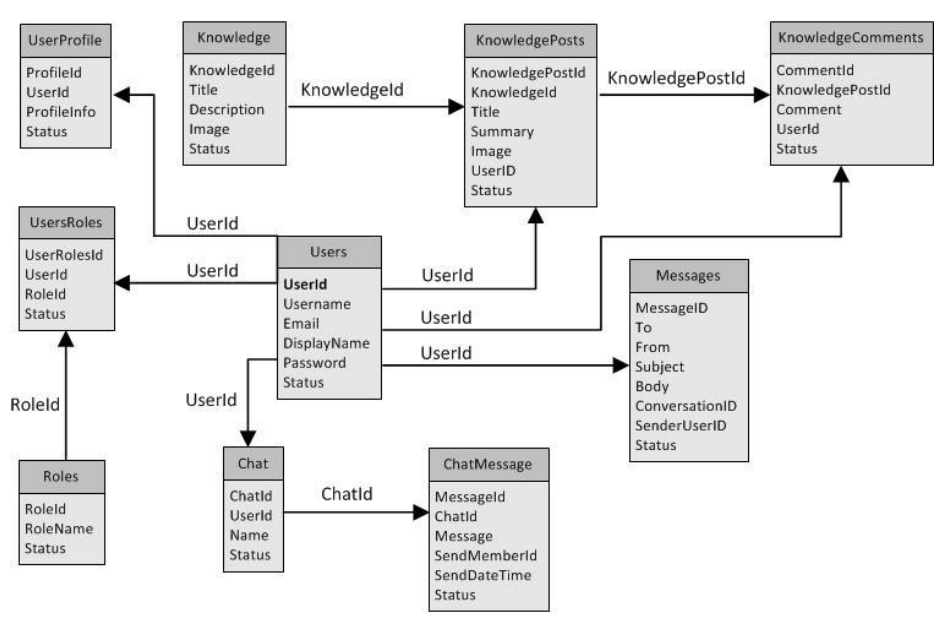

Gambar 4. Diagram Relasi

\subsection{Kontruksi Sistem}

\subsubsection{Lingkungan Konstruksi}

a) Hardware

Hardware atau perangkat keras yang digunakan untuk mengkonstruksi atau membangun knowledge management system dalam penelitian ini adalah sebagai berikut:

1) Processor: Intel ${ }^{\circledR}$ Core $^{\mathrm{TM}} \mathrm{i} 5-2410 \mathrm{M}: 2.30 \mathrm{GHz}$

2) Memory: 8GB DDR $665.1 \mathrm{MHz}$ SDRAM

3) Hard Disk: 500GB,5400rpm

4) Display: 13.3" HD (1366x768)

5) Grafis Video \& Memori: Terintegrasi Intel ${ }^{\circledR}$ HD Graphics 3000 \& ATU Radeon® dengan 1024 MB VRAM-switchable graphics

b) Software

Penerapan Knowledge Management System yang dibuat dengan menggunakan software yang berbasis web. Hal ini dikarenakan aplikasi yang berbasis web dapat dioperasikan dengan mudah, cukup mengetik alamat web aplikasi tersebut. Software tersebut terdiri dari empat kategori, yaitu software pemrograman, database, web browser, dan tools tambahan. Berikut daftar software yang digunakan dalam mengkonstruksi atau membuat prototipe dalam penelitian ini:

1) Visual Studio 2008

2) Microsoft SQL Server 2008

3) SQL Server Management Studio

4) Internet Information Services (IIS)

5) CMS DotNetNuke (DNN)

\subsubsection{Konstruksi Database}

Database knowledge management system ini dibangun menggunakan SQL Server 2008 database untuk menyimpan data yang dimasukan oleh aplikasi. Sedangkan Sql Sever Management Studio merupakan aplikasi visual yang dipergunakan untuk mempermudah dalam mengelola basis data dan berbasis desktop, Tool tersebut menyediakan model data, pengembangan $S Q L$, dan konfigurasi server basis data. CMS DotNetNuke sebagai aplikasi web yang di gunakan untuk mempercepat prooses pumbuatan system ini.

\subsubsection{Konstruksi Antarmuka}

Bagian ini akan menjelaskan kontruksi tampilan aplikasi knowledge management system. Untuk menjelaskan hasil konstruksi tersebut akan diberikan screenshot dari masing-masing tampilan, baik itu tampilan navigasi maupun halaman pada aplikasi yang dibangun dan gambar lainnya dilampirkan sebagai lampiran. 
a) Tampilan halaman login untuk pengguna

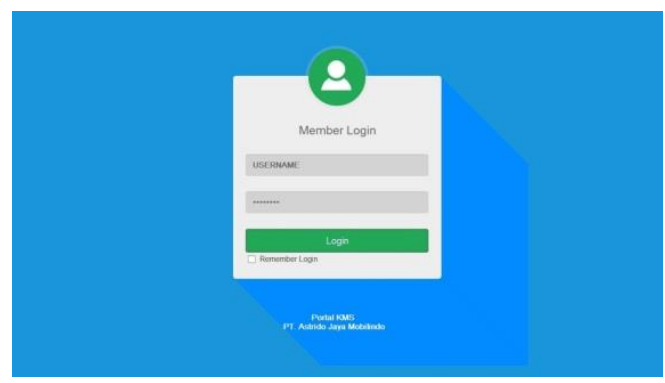

\section{Gambar 5. Tampilan Halaman Login Untuk Pengguna}

b) Tampilan halaman Home

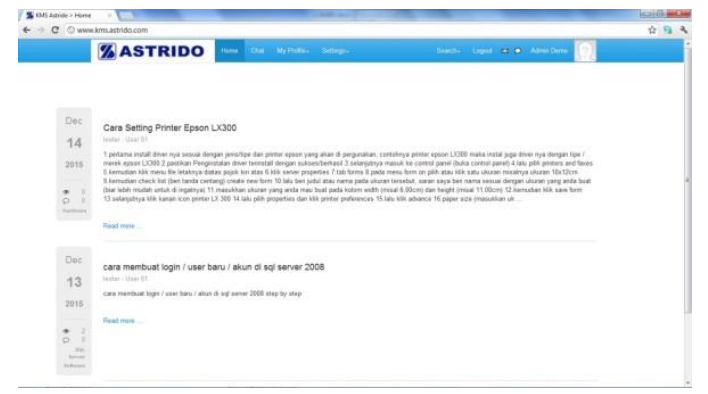

Gambar 6. Tampilan Halaman Home

c) Tampilan halaman chat

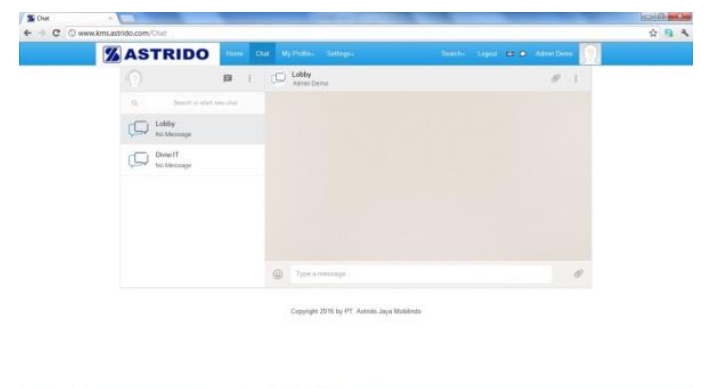

Gambar 7. Tampilan Halaman Chat

\subsection{Pengujian Sistem}

\subsubsection{Lingkungan Pengujian}

Lingkungan pengujian memberikan gambaran tentang spesifikasi hardware, software, dan jaringan yang digunakan oleh pengguna dalam proses pengujian sistem, baik pengujian validasi maupun pengujian kualitas. Spesifikasi tersebut diperoleh dalam proses observasi berdasarkan aspek sistem. Berikut ringkasan singkat spesifikasi perangkat keras dan perangkat lunak serta jaringan yang digunakan oleh pengguna untuk proses pengujian:

a) Hardware

1) PC Server dengan Processor Core i3 1.8 GHz, RAM 8GB

2) Wireless Router $150 \mathrm{mbps}$

3) Ponsel Android Minimum OS Android 2.3 Ginger Bread.

b) Software

Software PC Server di kantor PT. Astrido Jaya Mobilindo menggunakan sistem operasi Windows. Aplikasi web browser dalam pengembangan system. Berikut daftar software yang digunakan dalam lingkungan pengujian: 
1) Sistem Operasi Microsoft Windows Server 2008 R2

2) Web Browser Mozilla Firefox

3) SQL Server 2008

4) Internet Information Services (IIS)

\subsubsection{Hasil Pengujian Kualitas}

Dari beberapa pengujian yang di lakukan dengan beberapa tool maka hasil yang di dapatkan dapat di lihat pada tabel berikut:

Tabel 4. Hasil pengujian kualitas

\begin{tabular}{llll}
\hline No & Teknik pengujian & Keberhasilan & Kriteria \\
\hline 1 & Forum Group Discussion (FGD) & $100 \%$ & Diterima keseluruhan \\
2 & ISO 9126 & $79.43 \%$ & Baik \\
3 & Blackbox Testing & $100 \%$ & Baik \\
4 & Acunetix & $75 \%$ & Sudah cukup aman \\
\hline
\end{tabular}

\subsubsection{Kesimpulan Hasil Pengujian Kualitas Dan Pembuktian Hipotesis}

Berdasarkan hasil pengujian, pengujian untuk hipotesis kedua dalam penelitian ini dibuktikan bahwa kualitas penerapan knowledge management system yang dihasilkan jika diukur berdasarkan kualitas perangkat lunak model ISO 9126 mencapai harapan semula yaitu Baik. Hasil akhir kualitas perangkat lunak menurut responden adalah Baik dengan persentase tanggapan responden sebesar 79.43\%. Terakhir dari pengujian Blackbox Testing pengguna dapat menjalankan semua fungsi dengan baik. Hasil akhir dari pengujian dengan Acunetix adalah sudah cukup aman di pakai oleh pengguna.

\subsection{Implikasi Penelitian Dan Evaluasi Keseluruhan}

\subsubsection{Aspek Sistem}

Untuk mengimplementasikan penerapan knowledge management system perlu dilakukan peningkatan spesifikasi hardware yang digunakan sebagai server. Aplikasi dipasang di server local/intranet PT. Astrido Jaya Mobilindo.

Dari aspek perangkat lunak yang menggunakan ASP.NET memiliki peran penting dalam pengembangan web. Saat ini, perusahaan yang menyediakan jasa pengembangan ASP.NET sangat diminati karena mampu menyediakan fitur yang sangat baik dan berbagai solusi pengembangan web, fleksibilitas, dan keamanan yang efektif untuk pengembangan web. Dari sisi database sendiri yang menggunakan MS SQL Server 2008, dapat memasukan data yang cukup banyak karena MS SQL Server 2008 memiliki maksimal penyimpanan data yang sudah cukup besar. Peningkatan sarana dan prasarana dari pendukung sistem teknologi informasi yang ada disesuaikan dengan perkembangan parangkat dari teknologi informasi.

\subsubsection{Aspek Manajerial}

Penelitian ini bisa menjadi acuan bagi eksekutif dan staff untuk membiasakan menyimpan knowledge yang di miliki dan menyimpan informasi yang berhungungan dengan pekerjaan pada PT. Astrido Jaya Mobilindo. Dengan adanya system knowledge management system.

\subsubsection{Aspek Penelitian Lanjutan}

Dengan adanya penelitian ini maka para pihak akademis bisa menggunakan hasil penelitian sebagai referensi untuk penelitian yang sejenis dan bisa lebih mengembangkan lagi penelitian yang akan digunakan. Upaya untuk meningkatkan penelitian berkaitan dengan pengembangan penerapan knowledge management system dapat dilakukan dengan memperluas ruang lingkup penelitian.

\subsection{Rencana Implementasi Sistem}

Rencana implementasi sistem merupakan tahap awal dari penerapan sistem dan tujuan dari kegiatan implementasinya adalah agar sistem yang baru dapat beroperasi sesuai dengan yang diharapkan. 


\section{PENUTUP}

\subsection{Kesimpulan}

Berdasarkan hasil penelitian yang telah dibahas di bab sebelumnya, maka dalam penelitian penerapan knowledge management system pada pt. astrido jaya mobilindo ini dapat diambil kesimpulan sebagai berikut:

1) Model analisis, perancangan dan implementasi perangkat lunak untuk penerapan knowledge management system pada pt. astrido jaya mobilindo dapat berfungsi untuk menyimpan dan memanfaatkan knowledge yang dimiliki karyawan sehingga mempermudah karyawan dalam menangani suatu permasalahan.

2) Dengan melakukan beberapa tahap pengujian seperti FGD, ISO9126, Acunetix dan BlackBox, selain sesuai dengan kebutuhan sistem, pengujian juga dapat mempercepat kinerja dari sistem itu sendiri dan meminimalisir celah serangan dari luar seperti sql injection dan lain sebagainya.

\subsection{Saran}

Berdasarkan hasil penelitian, implikasi dan kesimpulan, selanjutnya peneliti dapat memberikan beberapa saran yang relevan dengan hasil penelitian. Saran ini berupa masukan-masukan yang ditujukan ke organisasi/obyek penelitian dan untuk penelitian selanjutnya.

a) Bagi Pihak PT. Astrido Jaya Mobilindo:

Dengan membudayakan sharing knowledge dapat meningkatkan kinerja karyawan. Dan knowledge dapat menjadi aset yang sangat berharga kedepannya bagi perusahaan. Tanpa membudayakan sharing knowledge pada karywan system KMS ini tidak akan bermanfaat. Jadi sangat penting bagi perusahaan dengan membudayakan sharing knowledge antar karyawan.

b) Bagi Penelitian Selanjutnya:

Dengan penelitian ini maka para pihak akademis bisa menggunakan hasil penelitian sebagai referensi untuk penelitian yang sejenis dan bisa lebih mengembangkan lagi penelitian yang akan digunakan.

\section{DAFTAR PUSTAKA}

[1] Darudiato, S. and Setiawan, K. 2013. "Kenowlwdge management: konsep dan metodologi". ULTIMA InfoSys. Vol. IV, No.1 Juni 2013〉, 11-17.

[2] Jeffrey, L., Kevin, C. (2004). Fundamentals of systems analysis and design methods. Boston: McGraw-Hill Irwin.

[3] Kandou, Y. L., Lengkong, V. P. K., and Sendow, G. 2016. "Pengaruh knowledge management, skill dan attitude terhadap kinerja karyawan (studi pad apt. bank sulutgo kantor pusat di manado)". Jurnal Berkala Ilmiah Efisiensi. Volume 16 No.01 Tahun 2016, 147-158.

[4] Kendal, K., and Kendal, J. (2001). Systems Analysis and Design Fifth Edition. New York: Prentice Hall.

[5] McLeod, R., and Schell, G. (2007). Management Information Systems, $10^{\text {th }}$ Edition. New York: Prentice Hall.

[6] Nazir, M. 2005. "Preliminary study: KM practices in the small medium software companies". Journal of knowledge management practice. ,2.

[7] Nonaka, I., and Takeuchi, H. (1995). The knowledge creating company: How Japanese Companies Create the Dynamics of Innovation. Jepang: Oxford University Press.

[8] Retnoningsih, Endang. 2013. "Knowledge management system(kms) dalam meningkatkan inovasi lppm perguruan tinggi”. Evolusi. Vol. 1 No.1 September 2013. 76-85.

[9] Sari, W. K., and Tania K. D. 2014 "Penerapan knowledge management system (kms) berbasis web studi kasus bagian teknisi dan jaringan fakultas ilmu komputer universitas sriwijaya”. Jurnal Sistem Informasi (JSI). Vol. 6, No. 2 oktober 2014. 681-688.

[10] Wijaya, A. E. 2014. "Model penerapan knowledge management system untuk penyusunan tugas akhir berbasis teknologi mobile menggunakan j2me (studi kasus stmik subang)". Seminar Nasional Informatika 2014 (semnasIF 2014). 190-195. 